\title{
INFLACIÓN SUBYACENTE Y ANÁLISIS POR DESCOMPOSICIÓN: UNA RADIOGRAFÍA DE LA INFLACIÓN EN TIEMPOS DE ESTABILIDAD
}

\section{Ernesto Cupé C.}

\section{RESUMEN}

El documento consta de dos ejes centrales. El primero es de carácter metodológico; tomando en cuenta las características de la economía boliviana, se desarrolla la descomposición de la inflación por componentes principales y se propone, implementa y valida econométricamente, una medida de inflación subyacente. El segundo, consiste en una aplicación de la metodología a la identificación de características estructurales de la inflación en Bolivia, incluyendo un análisis de precios en la coyuntura actual. Se obtiene una radiografía de la inflación durante el actual período de estabilidad en precios, consolidada en 1993 cuando la inflación pasa a ser de un sólo dígito; destacan los cambios en la estructura de la inflación, con servicios básicos como el componente más inflacionario de la economía, por una parte, y el sistemático deterioro de precios relativos de los productos agrícolas no industriales, por otra. Esta radiografía incluye la caracterización de la relación de largo plazo entre inflación general y subyacente como cointegradas, además de la relación de corto plazo expresada como estacionariedad de media cero de la altamente volátil inflación no subyacente respecto a la estable inflación subyacente. La evidencia empírica puesta de manifiesto en este estudio, contribuye a comprender mejor el origen de los conflictos sociales en los años postcapitalización y los actuales movimientos reivindicativos surgidos en el área rural principalmente.

Palabras Clave: Inflación, Inflación Subyacente, Componentes Principales, Términos de Intercambio Internos, Estacionariedad, Cointegración. 